Research Article

\title{
Coordinated Development of Regional Complex System: A Niche-Based Study
}

\author{
Jianling Li $\mathbb{D}^{1},{ }^{1}$ Xiang Fan, ${ }^{1}$ Yufei Bai, ${ }^{2}$ and Jingjing Zhang ${ }^{1}$ \\ ${ }^{1}$ Business College of Beijing Union University, Beijing 100025, China \\ ${ }^{2}$ Capital University of Economics and Business, Beijing 100070, China \\ Correspondence should be addressed to Jianling Li; jianling.li@buu.edu.cn
}

Received 25 August 2021; Accepted 21 October 2021; Published 16 November 2021

Academic Editor: Daqing Gong

Copyright (c) 2021 Jianling Li et al. This is an open access article distributed under the Creative Commons Attribution License, which permits unrestricted use, distribution, and reproduction in any medium, provided the original work is properly cited.

Taking Beijing-Tianjin-Hebei as an example, it analyzes the comprehensive competitiveness of Beijing, Tianjin, and Hebei. It selects four dimensions: economic dimension, social dimension, environmental dimension, and technological dimension. From a new perspective, it explores the application of niche theory in regional synergy. Based on the analysis of the ecological niche, the coordination degree model of the composite system is further used to calculate the status quo of the coordinated development of the Beijing-Tianjin-Hebei region from 2013 to 2019. The results show that Beijing has the highest ecological niche, followed by Tianjin, and Hebei is the weakest. In 2019, the Beijing-Tianjin-Hebei region is at a good level of coordination, with the social subsystem having the highest order and the technological subsystem having the lowest order. Based on this, it is proposed that the Beijing-Tianjin-Hebei regions should be scientifically positioned, the overall need to be aligned with international trends, and the internal planning should be integrated to further enhance the level of cooperation in the Beijing-Tianjin-Hebei region.

\section{Introduction}

Regional coordinated development is an important part of China's high-quality development. Improving the coordinated development level of Beijing-Tianjin-Hebei is a key strategy for China's regional coordinated development. Based on the niche perspective, this paper studies the coordinated development of regional complex systems. Since China promulgated the "Beijing-Tianjin-Hebei Coordinated Development Plan" in 2015, the Beijing-Tianjin-Hebei region has initially demonstrated the advantages of coordinated development under the guidance of policies and has achieved obvious results. Today, the coordinated development of urban agglomerations is still an important national development strategy. The Fifth Plenary Session of the 19th Central Committee analyzed the profound and complex changes and pointed out that the development of urban agglomerations has played a vital role in country's development. At present, the Beijing-Tianjin-Hebei region is already the economic center with the best location, the largest scale, and the strongest innovation capability in northern country. As the capital of China, after long-term development, Beijing's strong comprehensive strength will inevitably benefit Tianjin and other cities in Hebei. However, there are still some problems in the development of BeijingTianjin-Hebei regional coordination, such as the lack of coordination of various systems and insufficient resource utilization, which need to be resolved urgently. Therefore, in the context of high-quality economic development in China, it is of great practical significance to strengthen the research on the coordinated development of the Beijing-TianjinHebei region.

\section{Literature Review}

Regarding the definition of ecological niche, scholars have different studies. Grinnell first proposed the concept of niche in 1917 and defined it as "the final distribution unit occupied by exactly one species or subspecies."Charles Elton adopted the status of animals in the biological environment and their relationship with food and natural enemies raises the functional niche. Hutchinson considered the concept of 
niche mathematically from various aspects such as space and resource utilization and proposed $n$-dimensional hyper-volume. Since the 1990s, domestic and foreign scholars have deduced the niche theory from the natural ecosystem to the social-economic-natural composite ecosystem and carried out the relative advantages of the natural resources, environmental functions, and economic and social functions of each ecological unit [1-3].

The coordinated development of the Beijing-TianjinHebei region has been a hot research direction for scholars in recent years. The research disciplines are mainly distributed in the fields of economy, management, education, politics and law, geography, environmental science, and resource utilization and have also achieved rich research results [4]. On the one hand, the research direction is the research on the influencing factors of the Beijing-TianjinHebei collaborative innovation performance, aiming to find new growth points that promote the collaborative innovation of the Beijing-Tianjin-Hebei region [5]. Besides, it focuses on the analysis of the important progress of the coordinated development of Beijing-Tianjin-Hebei, starting from different aspects of coordination and clarifying the existence of industries, public services, transportation, ecology, and land use in the Beijing-Tianjin-Hebei region since the coordinated development. In combination with the current domestic and foreign environmental background of our country, the idea of coordinated development in the future is pointed out [6-11]. In addition to the separate study of the Beijing-Tianjin-Hebei region, some scholars have compared the Beijing-Tianjin-Hebei urban agglomeration with the Yangtze River Delta urban agglomeration and the Pearl River Delta urban agglomeration and found the coordinated development of the Beijing-Tianjin-Hebei region through horizontal comparisons [12-16].

On the basis of previous studies, the difference of this article is that based on the perspective of niche, it uses quantitative methods to study the status quo of coordinated development in the Beijing-Tianjin-Hebei region. Through the establishment of index calculations, the comprehensive niche of Beijing, Tianjin, and Hebei province is obtained. The size of the position represents the size of the regional competitiveness, and further analysis to find the future development direction of Beijing, Tianjin, and Hebei Province is carried out. Based on the analysis of the ecological niche, the Beijing-Tianjin-Hebei regional composite system is further established, and the coordination degree model of the composite system is used to calculate the order and four of the economic subsystem, social subsystem, ecological subsystem, and technological subsystem from 2013 to 2019. Dynamic changes in the degree of synergy of the composite system of each system are observed, so as to analyze the changes in the coordinated development of the Beijing-Tianjin-Hebei region.

\section{Research Method}

3.1. Niche-Related Theories. Niche theory is originated from ecology and is one of the most widely used theories in ecology. A commonly accepted definition is that niche refers to the time, space location, and functional relationship of species in communities. The concept of urban niche is given here as the spatial position occupied by a certain city and the function and existing influence played by a certain city in a certain urban ecological environment system. To analyze the niche size of Beijing, Tianjin, and Hebei province in the Beijing-Tianjin-Hebei region, not only the niche size of each index factor must be analyzed but also the comprehensive niche size of the three cities must be calculated. The connotation of the research niche is to pursue resource sharing in the ecosystem, mutual benefit, and symbiosis of each subject, find their respective spatial locations to achieve healthy competition, and achieve overall sustainable development. This article draws on relevant domestic and foreign literature to establish an index model [17-19].

3.2. Niche Calculation Formula. Based on the niche calculation formula given by Zhu [20], the niche calculation formula used in this article is as follows:

$$
\begin{aligned}
N_{i} & =\frac{\left(S_{i}+A_{i} P_{i}\right)}{\sum_{j=1}^{n}\left(S_{j}+A_{j} P_{j}\right)}, \\
M_{i j} & =\sum_{i=1}^{n} \frac{N_{i j}}{n} .
\end{aligned}
$$

In the formula, $N_{i}$ is the niche of a certain index factor $i$; $M_{i j}$ is the comprehensive niche of a city; $N_{i j}$ is the niche of a single index factor of a city; $n$ is the number of factors; and $j$ is the number of cities.

\subsection{Data Processing}

3.3.1. Standardization of the Indicators. Since the measurement units of various indicators are not uniform, the data must be standardized before calculation. This paper uses the min-max standardization method (equation (3)) to standardize the raw data of the index selected by the sequence parameter:

$$
\begin{gathered}
\text { positive indicators: } X_{i j^{\prime}}=\frac{X_{i j}-X_{\min }}{X_{\max }-X_{\min }}, \\
\text { negative indicators: } X_{i j^{\prime}}=\frac{X_{\max }-X_{i j}}{X_{\max }-X_{\min }} .
\end{gathered}
$$

$X_{i j}$ is the original index value, and $X_{i j}$ is the index value after standardization.

\subsubsection{Determination of the Indicator Weight.}

$$
\begin{aligned}
A_{i j} & =\frac{X_{i j^{\prime}}}{\sum_{i=1}^{n} X_{i j^{\prime}}}, \\
e_{j} & =-\left(\frac{1}{\ln n}\right) \sum_{i=1}^{n} A_{i j} \ln A_{i j},
\end{aligned}
$$




$$
a_{j}=\frac{\left(1-e_{j}\right)}{\sum_{j=1}^{n}\left(1-e_{j}\right)} .
$$

3.4. Niche Index System Construction. When selecting niche evaluation indicators, this paper adheres to the principles of rationality, operability, and data availability and constructs four dimensions of economy, society, environment, and technology to measure the three dimensions of the Beijing-Tianjin-Hebei region. On the basis of four dimensions, 16 indicator factors were specifically selected through screening. The specific evaluation index system is shown in Table 1 .

3.5. Synergy Model of Composite System. Regarding the Beijing-Tianjin-Hebei region as a composite system $S, S=$ $\{S 1, S 2, S 3, S 4\}, i \in[1,4]$, set the order parameter in the development process as $X_{i j}=\left(X_{i 1}, X_{i 2}, \ldots, X_{i n}\right), n \geq 2$, $\beta_{i k} \leq X_{i j} \leq \alpha_{i k}, k \varepsilon[1, n]$, where $\alpha_{i k}$ and $\beta_{i k}$ are the upper limit and lower limit of the order parameter. The calculation formula is as follows:

$$
\begin{gathered}
U_{i}\left(X_{i j}\right)= \begin{cases}\frac{X_{i j}-\beta_{i j}}{\alpha_{i j}-\beta_{i j}}, & j \in[1, m], \\
\frac{\alpha_{i j}-X_{i j}}{\alpha_{i j}-\beta_{i j}}, & j \in[m+1, n],\end{cases} \\
U_{i}\left(X_{i}\right)=\sqrt[n]{\prod_{j=1}^{n} U_{i}\left(X_{i j}\right),} \\
\eta=\lambda \sqrt[n]{\left|\prod_{i=1}^{n}\left(U_{i}^{1}\left(X_{i}\right)-U_{i}^{0}\left(X_{i}\right)\right)\right|}
\end{gathered}
$$

In the formula, the value range of $\eta$ is $-1 \sim 1$. The larger the value of $\eta$, the higher the degree of synergy. 0 is defined as the base period, and 1 is defined as the reporting period. $U_{i}^{1}\left(X_{i}\right) \geq U_{i}^{0}\left(X_{i}\right)$, the value of $\lambda$ is $1 ; U_{i}^{1}\left(X_{i}\right) \leq U_{i}^{0}\left(X_{i}\right)$, the value of $\lambda$ is -1 .

3.6. Index System. This paper divides the composite system into four major systems: economic subsystem, social subsystem, ecological subsystem, and technological subsystem. Each system contains 4 indicators. The specific indicators are selected as shown in Table 2.

\section{Research Results}

4.1. Niche Calculation and Evaluation. The data obtained from the selected indicators in this article are mainly derived from the 2016-2019 China Statistical Yearbook. The metric for "state" is the present value of each indicator factor in 2019, and the metric for "potential" is the annual average growth of each indicator factor. Taking time as the dimensional conversion coefficient, 1 year is selected in this paper, that is, the dimensional conversion coefficient is 1 . The value range of niche is between 0 and 1 , and the sum is 1 .

The niche values of each influencing factor are shown in Table 3.

The economic, social, environmental, technological, and comprehensive niche values and rankings of the three regions of Beijing-Tianjin-Hebei are calculated by formula (2). The niche values of the Beijing-Tianjin-Hebei region are shown in Figure 1.

According to the theory of niche, the greater the niche value of the area, the greater the comprehensive competitiveness, and the greater the impact on the environment of the surrounding area. It can be clearly seen from Figure 1 that Beijing's niche ranking in all dimensions is the first, and the comprehensive niche is also the first, close to 0.5, indicating that Beijing's comprehensive development status is the best. In the environmental dimensions, Beijing has focused on environmental protection and governance in recent years; Especially in terms of industrial development, the tertiary industry is the main driving force for the rapid development and upgrading of Beijing's industries. Beijing has become the main position for the transformation and upgrading of the Beijing-Tianjin-Hebei region. At the same time, advanced science and technology are supported to promote the high-level development of Beijing as a whole.

Tianjin ranks second in the comprehensive niche, economic, and technological. However, Hebei is slightly higher than Tianjin in terms of social and environmental dimensions, indicating that Tianjin's environmental problems are more prominent. The substantial reduction in per capita green area has reduced its environmental niche. The main reason is that, in recent years, Tianjin has relied on advanced industrial manufacturing to drive economic development. Industrial land has taken up green land, thus increasing the burden on the environment. At the same time, Tianjin's social development is weak, and the per capita retail sales of consumer goods and the number of medical and health institutions have reduced the level of social development in Tianjin. Due to the rapid development of Tianjin in the early stage, Tianjin is currently in a period of slow growth.

Hebei has the lowest comprehensive ecological niche, the weakest overall competitiveness, and the smallest role in the region. The comprehensive niche is in urgent need of improvement. In terms of economic development and technological innovation, the niche ranks are the lowest. However, Hebei has been committed to environmental pollution control and social infrastructure construction in recent years. The overall development is rapid, and there is a large room for growth. The industry is mainly driven by the primary and secondary industries. Traditional industries still occupy a major position, and lack of advanced tertiary industry drives economic development. The slow development of science and technology and low innovation capabilities are the main reasons hindering the development of Hebei. 
TABLE 1: Evaluation index system of the niche.

\begin{tabular}{|c|c|c|}
\hline Target & Dimension & Index \\
\hline \multirow{16}{*}{ Niche (A1) } & \multirow{4}{*}{ Economy (B1) } & GDP per capita $(\mathrm{C} 1)$ \\
\hline & & Per capita consumption expenditure of residents (C2) \\
\hline & & Per capita disposable income of residents $(\mathrm{C} 3)$ \\
\hline & & Local fiscal revenue $(\mathrm{C} 4)$ \\
\hline & \multirow{5}{*}{ Society (B2) } & Per capita retail sales of consumer goods (C5) \\
\hline & & The number of ordinary colleges and universities (C6) \\
\hline & & Per capita possession of public book collection (C7) \\
\hline & & Number of medical and health institutions per capita (C8) \\
\hline & & Green area per capita (C9) \\
\hline & \multirow{3}{*}{ Environment (B3) } & Comprehensive utilization rate of solid waste $(\mathrm{C} 10)$ \\
\hline & & Harmless treatment rate of domestic garbage $(\mathrm{C} 11)$ \\
\hline & & Forest cover rate $(\mathrm{C} 12)$ \\
\hline & \multirow{4}{*}{ Technology (B4) } & Number of R\&D personnel (C13) \\
\hline & & Number of valid invention patents (C14) \\
\hline & & Number of technical market transactions $(\mathrm{C} 15)$ \\
\hline & & Number of new product development projects of industrial enterprises (C16) \\
\hline
\end{tabular}

TABLE 2: Index system of the composite system.

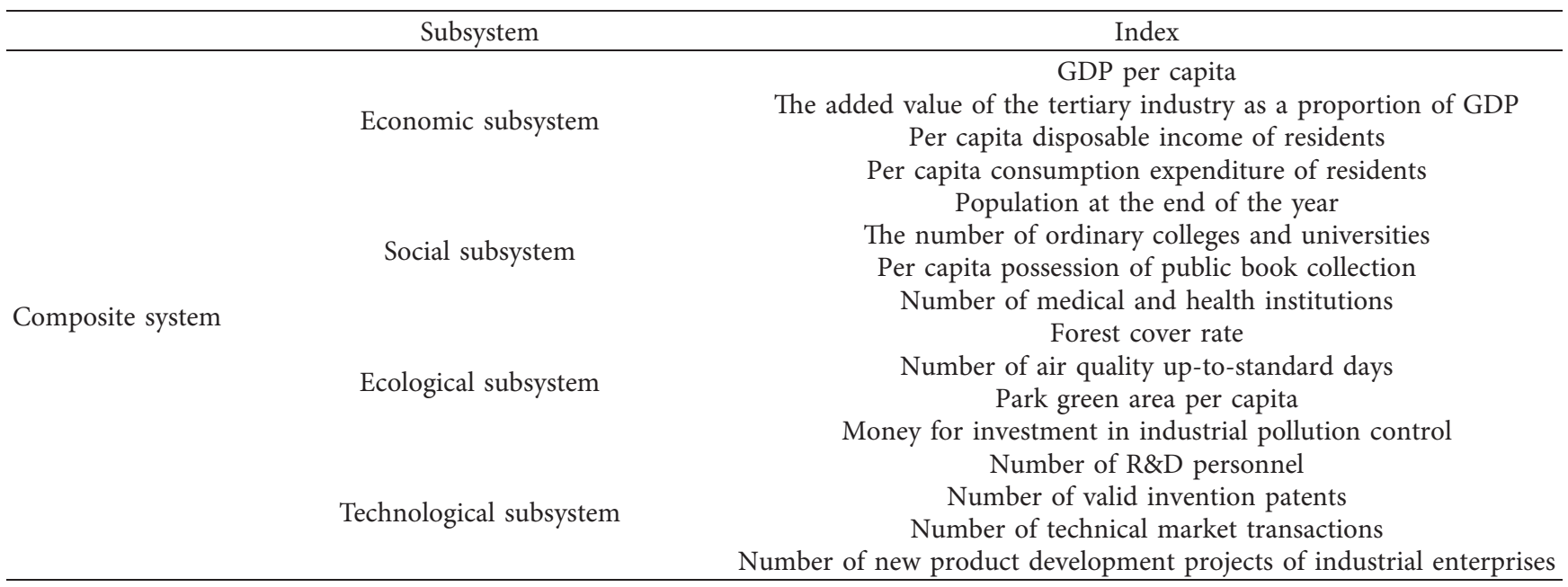

TABLE 3: The influencing factor values of Beijing-Tianjin-Hebei region.

\begin{tabular}{|c|c|c|c|c|c|c|c|c|c|c|c|c|c|c|c|c|}
\hline & $\mathrm{C} 1$ & $\mathrm{C} 2$ & C3 & $\mathrm{C} 4$ & C5 & C6 & C7 & $\mathrm{C} 8$ & C9 & $\mathrm{C} 10$ & $\mathrm{C} 11$ & $\mathrm{C} 12$ & $\mathrm{C} 13$ & $\mathrm{C} 14$ & C15 & $\mathrm{C} 16$ \\
\hline Beijing & 0.4327 & 0.4582 & 0.5004 & 0.5188 & 0.5487 & 0.3407 & 0.4519 & 0.2994 & 0.4692 & 0.2810 & 0.3399 & 0.5379 & 0.2769 & 0.5201 & 0.8089 & 0.3167 \\
\hline Tianjin & 0.3779 & 0.6261 & 0.3113 & 0.1607 & 0.3059 & 0.2037 & 0.4263 & 0.2153 & 0.1319 & 0.4512 & 0.3212 & 0.1485 & 0.3276 & 0.2485 & 0.1221 & 0.3356 \\
\hline Hebei & 0.1548 & 0.1952 & 0.1884 & 0.3205 & 0.1455 & 0.4556 & 0.1218 & 0.4853 & 0.3989 & 0.2678 & 0.3389 & 0.3137 & 0.3956 & 0.2313 & 0.0690 & 0.3477 \\
\hline
\end{tabular}

4.2. The Order Degree of the Subsystem. Substituting the data into formulas (7) and (8), the order degree of each subsystem in the Beijing-Tianjin-Hebei region from 2013 to 2019 can be obtained. (Table 4).

Figure 2 shows the changes in the orderliness of the four subsystems in the Beijing-Tianjin-Hebei region from 2013 to 2019. Putting the four subsystems together we can clearly see the advantages and disadvantages of the coordinated development of the four dimensions in the regional development process.

It can be seen from Figure 2 that, in 2013, the order of the ecological and technological subsystems in the Beijing-
Tianjin-Hebei region was not 0 , but the order of the economic and social subsystems was both 0 . It shows that, in 2013, the economic gap within the region was large, the distribution of social infrastructure was extremely uneven, and the degree of economic and social development was not high. After several years of development, the gap between the regions has been reduced, and coordinated development has promoted the overall development of economic and social infrastructure. In contrast, the orderliness of ecological subsystems with a certain foundation is gradually increasing, but the growth rate is slower. In 2019, the Beijing-Tianjin-Hebei region has the highest 


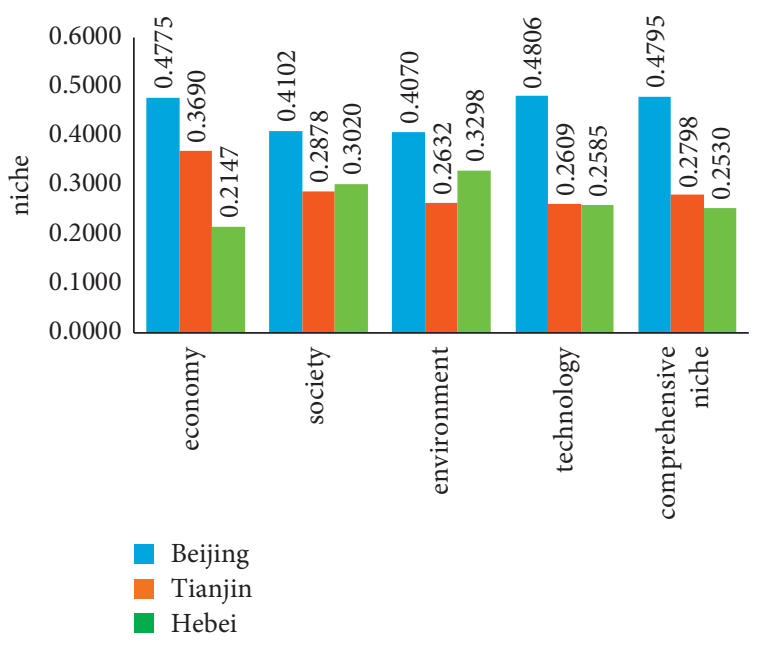

FIgure 1: The comprehensive niche value of Beijing-Tianjin-Hebei region.

TABle 4: Order degree of the Beijing-Tianjin-Hebei regional subsystem.

\begin{tabular}{ccccc}
\hline Year & Economic subsystem & Social subsystem & Ecological subsystem & Technological subsystem \\
\hline 2013 & 0.0000 & 0.0000 & 0.1531 & 0.2270 \\
2014 & 0.1409 & 0.1424 & 0.1561 & 0.4028 \\
2015 & 0.3054 & 0.2996 & 0.3897 & 0.3804 \\
2016 & 0.4828 & 0.4471 & 0.5601 & 0.5002 \\
2017 & 0.6508 & 0.6661 & 0.6496 & 0.5093 \\
2018 & 0.8093 & 0.8775 & 0.7248 & 0.5559 \\
2019 & 0.9763 & 1.0000 & 0.8257 & 0.7500 \\
\hline
\end{tabular}

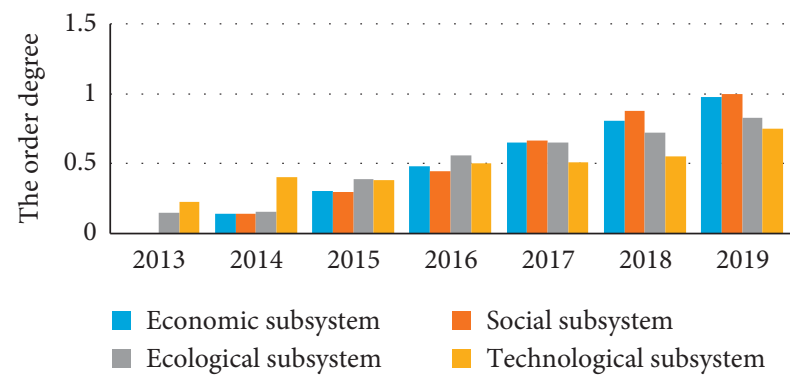

Figure 2: The order degree of four subsystems.

degree of order in the social subsystem, reaching 1,0000, indicating that the social development trend of the three regions is the same and developing in a more orderly direction. Ranked second is the economic subsystem, with an orderly degree of 0.9763 . The orderly degree of coordinated economic development is also very high, and the economic development of various cities continues to improve. The ecological subsystem and the science and technology subsystem ranked third and fourth, respectively, especially the order degree of the science and technology subsystem was only 0.7500 , which affected the degree of coordination of the Beijing-Tianjin-Hebei composite system. In the future coordinated development, the region should focus on technological synergy.
4.3. Coordination Degree of the Composite System. Substitute the calculated order degree of the subsystem into formula (9) to calculate the composite synergy degree of the Beijing-Tianjin-Hebei region. The result of the synergy degree is shown in Table 5. For comparison between different years, this paper uses 2013 as Base period.

It can be seen from Table 5 that, from 2014 to 2019, the collaborative development trend between subsystems is consistent, showing an increase in the degree of collaboration of the entire composite system. The order degree of the four subsystems is increased, and the value of $\lambda$ is positive, and finally, the coordination level is obtained as the cooperative development state. This shows that, in the process of coordinated development in the Beijing-TianjinHebei region, economic development, social development, ecological environment, and technological innovation are all developing positive trends, and they will continue to grow in the future. The synergy evaluation was only a low degree of synergy in 2014. In 2015, the degree of synergy increased significantly. This was mainly because the coordinated development of Beijing-Tianjin-Hebei promoted the coordinated development of cities in the Beijing-Tianjin-Hebei region and strengthened the contact of the subsystems. Only when the order of all systems increases, the entire composite system will show a cooperative state. Until 2019, the highest degree of synergy reached 0.7655 , and the degree of synergy was at a good level of synergy. There is still a lot of room for 
TABle 5: The degree of coordination of the Beijing-Tianjin-Hebei complex system.

\begin{tabular}{ccccc}
\hline Year & Beijing-Tianjin-Hebei region & Beijing & Tianjin & Hebei \\
\hline 2014 & 0.0568 & -0.1157 & -0.1419 & 0.1446 \\
2015 & 0.2400 & -0.2889 & 0.2199 & 0.2434 \\
2016 & 0.3936 & -0.3171 & 0.3876 & 0.4257 \\
2017 & 0.4965 & -0.2609 & 0.4615 & 0.5552 \\
2018 & 0.6045 & -0.1572 & 0.5163 & 0.7120 \\
2019 & 0.7655 & 0.5780 & 0.5802 & 0.8692 \\
\hline
\end{tabular}

development in the future. The high-quality coordinated development of Beijing-Tianjin-Hebei needs more efforts.

The synergy degree of Beijing's composite system was negative from 2014 to 2018 because of the decrease in the orderliness of the technological subsystems, which led to a state of noncoordination. Until 2019, the degree of synergy became positive, at the general level of synergy. Tianjin's synergy degree was negative in 2014, which was also due to the orderly decline of the technological subsystems, which led to $\lambda$ taking -1 , showing a state of non-coordination. However, from 2015 to 2019, the synergy degree became positive and continued to increase. By 2019, the synergy level will be the general state of synergy. In comparison, Hebei is developing rapidly, and the degree of synergy of the composite system is all positive, indicating that the four subsystems in Hebei are in a state of coordinated development. Since the coordinated development of Beijing-TianjinHebei, the development of Hebei has been greatly promoted. In 2019, the coordination degree of the Hebei composite system reached 0.8692 , which is a high level of coordination and surpassed the overall coordination degree of BeijingTianjin-Hebei (Figure 3).

\section{Discussion and Conclusion}

Based on the perspective of niche, this paper calculates the niche values of Beijing, Tianjin, and Hebei. The results show that Beijing ranks first in economy, society, environment, technology, and comprehensive niche. Tianjin ranks second in comprehensive ecological niche, but ranks third in social and environmental dimensions. It is a weak link in development and urgently needs to improve the urban ecological environment. Hebei ranks third in comprehensive niche. Economic development and technological development are still the key to restricting Hebei's development, and it is in a weak position. In the research on the synergy of the Beijing-Tianjin-Hebei regional composite system, from 2014 to 2019, the synergy increased year by year, and the increase was the largest in 2015. By 2019, the synergy of the Beijing-Tianjin-Hebei regional composite system is only in a good state of synergy. Among the subsystems, the technological subsystem has the lowest degree of order, which is the main reason that hinders the high level of collaboration. This shows that, in the future coordinated development process, Beijing-Tianjin-Hebei should increase technological coordination, break administrative barriers and innovation boundaries, realize technological exchanges between the three places, and finally make up for shortcomings. Analyzing from the perspective of niche, the Beijing-TianjinHebei ecological synergy is in a weak link. In the process of

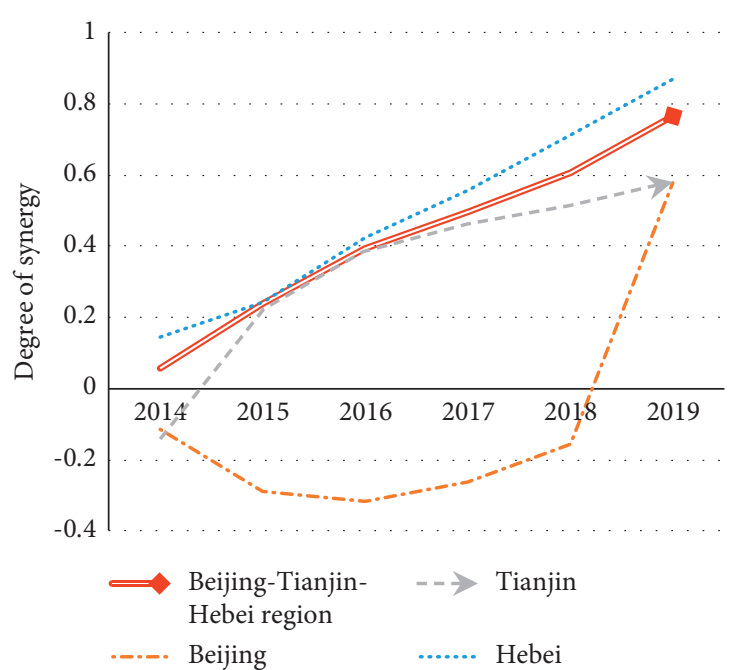

Figure 3: The degree of synergy of the Beijing-Tianjin-Hebei complex system.

coordination, ecological governance should be strengthened, unified standards for ecological protection should be established, relevant policies should be issued, and ecological compensation mechanisms should be established and improved. With the help of the separation strategy, expansion strategy, and symbiosis strategy in the concept of niche, the goal of high-quality coordinated development in the BeijingTianjin-Hebei region is achieved.

5.1. Scientific Positioning of Various Places and Separation of Ecological Niches. In the coordinated development of Beijing-Tianjin-Hebei, it is necessary to separate the ecosystem positions occupied by each subject to avoid homogenous competition due to the same resource. First of all, Beijing, as the city with the highest niche in the Beijing-Tianjin-Hebei region, must continue to strengthen Beijing's core position and at the same time relieve Beijing's noncapital functions, and transfer high-consumption and high-polluting industries. In the comprehensive niche analysis, Tianjin and Hebei both compete for more development. Committed to building Tianjin into a national advanced manufacturing research and development base, a northern international shipping core area, a financial innovation operation demonstration zone, and a reform first demonstration zone, use the unique advantages of the port to find a path suitable for its own development. Hebei has a vast territory. In the future development, Hebei will be transformed into an important base for modern commerce and logistics in the country, a pilot zone for industrial transformation and upgrading, a demonstration zone for new urbanization and urban-rural coordination, and a support zone for the Beijing-TianjinHebei ecological environment. Among them, Zhangjiakou, Chengde, and Qinhuangdao give full play to the advantages of natural ecology and coastal resources to create characteristic functional cities serving the capital; Xiong'an undertakes some of the capital's administrative institutions, universities, scientific research institutes, medical and elderly care etc., and establishes scientific and technological 
innovation centers. Handan and Tangshan are heavy industry clusters, and the formation of clusters is also conducive to the upgrading of industrial structure.

5.2. Following the International Trends and Expanding the Niche. The expansion theory of niche points out that the main body in the ecosystem should evolve continuously, through evolution to improve their own survival ability, and obtain long-term development. Based on this theory, cities in the Beijing-Tianjin-Hebei region should actively expand development channels, absorb high-quality resources, and take the initiative to occupy the market based on their own advantages to avoid a decline in urban competitiveness. On the one hand, all regions of Beijing-Tianjin-Hebei must take the initiative to find new development directions and broaden their ecological niches. On the other hand, it is necessary to enhance the competitiveness of the entire region, seize the opportunity of the "Belt and Road," expand the level of opening up, introduce high-quality development resources at home and abroad, open up new market space, and build a world economic core area with strong competitiveness.

5.3. Regional Integration Planning to Realize Ecological Symbiosis. Beijing, Tianjin, and Hebei should strengthen communication and ties and achieve coordinated development in industries, ecological environment management, transportation, and social public infrastructure, so as to form a coordinated and symbiotic Beijing-Tianjin-Hebei ecosystem. First, the Beijing-Tianjin-Hebei region accelerates the coordinated development of industries, builds a modern green industrial system, cultivates world-class industrial clusters dominated by the tertiary industry, and accelerates the development of 5G, artificial intelligence, big data, Internet of Things, medicine, and e-commerce. Second, in terms of ecological environment management, the region should build a comprehensive ecological environment management system, from the atmosphere to the ground to the underground and from the city to the countryside, improve the ecological compensation mechanism, and form a three-dimensional and comprehensive ecological management system. Third, in terms of transportation, the Beijing-Tianjin-Hebei region should speed up the construction of a transportation network between major cities, including railways, highways, and aviation, and step up the construction of the Xiongan comprehensive transportation network to enhance overall transportation capacity. Finally, technological synergy is a weak link in coordinated development, and regions should accelerate the coordinated development of science and technology. The emphasis is on improving the sharing efficiency of science and technology and then improving and consolidating the platforms and carriers for technological innovation in the three places. Tianjin and Hebei should connect with the capital and create a service system with high standards, new mechanisms, and excellent ecology. Do a good job in undertaking the guarantee of high-tech innovation industries and raise the level of technological innovation in Beijing, Tianjin, and Hebei.

\section{Data Availability}

The research data of this paper are from China Statistical Yearbook, Hebei Statistical Yearbook, and official website. These data are publicly available online. We calculated, analyzed, and processed the data on the basis of these existing data.

\section{Conflicts of Interest}

The authors declare that there are no conflicts of interest.

\section{Acknowledgments}

This work was supported by the key project of Beijing Municipal Social Science Foundation (18YJA003) and TopNotch Plan Project for Strengthening Schools with Talents (BPHR2020BS01).

\section{References}

[1] J. Grinnell, "Field tests of theories concerning distributional contro," The American Naturalist, vol. 51, no. 602, pp. 115-128, 1917.

[2] M. Jose, F. Palomares, and M. Delibes, "Niche relations among three sympatric mediterranean carnivores," Oecologia, vol. 121, no. 1, pp. 138-148, 1999.

[3] F. Palomares, P. Ferreras, J. M. Fedriani, and M. Delibes, "Spatial relationships between iberian Lynx and other carnivores in an area of south-western Spain," Journal of Applied Ecology, vol. 33, no. 1, pp. 5-13, 1996.

[4] Z. J. Wu, Z. L. Han, and L. X. Zhao, "Analysis on the research situation and hot spots of the collaborative development of beijing-tianjin-hebei," Economics and Management, vol. 35, no. 3, pp. 31-38, 2021.

[5] B. Y. Zhao, "Analysis of influencing factors of collaborative innovation performance in beijing-tianjin-hebei--based on the spatial dubin model," Business Economy, vol. 1, pp. 162166, 2021.

[6] P. Svogzlys, "The structure of model for new services development," Journal of System and Management Sciences, vol. 10, pp. 21-39, 2020.

[7] M. Johnson and C. Christensen, "Reinventing your business model," Harvard Business Review, vol. 87, no. 4, p. 49, 2009.

[8] J. L. Li, "Research on the development strategy of regional ecological innovation in beijing-tianjin-hebei region," Chinese University Science \& Technology, vol. 04, pp. 36-38, 2016.

[9] J. Zhang, Y. Bai, J. Li, and X. Fan, "Applying an entropy method to evaluate regional traffic development from a niche perspective," Journal of Intelligent and Fuzzy Systems, vol. 41, no. 4, pp. 4785-4791, 2021.

[10] G. A. Amorim, L. A. S. Lopes, and O. S. Silva Junior, "Discreteevent-based railway simulation model for eco-efficiencyevaluation," International Journal of Simulation Modelling, vol. 19, no. 3, pp. 375-386, 2020.

[11] S. Q. Zhao, G. Y. Wang, and H. F. An, "Study on cross-regional allocation of construction land in beijing-tianjin-hebei region based on differentiation," IOP Conference Series: Materials Science and Engineering, vol. 371, no. 1, 2018.

[12] J. W. Sun and Q. Yuan, “The comparison and evolutionary key research of beijing-tianjin-hebei coordinated development strategy," Comparative Economic \& Social Systems, vol. 05, pp. 1-11, 2014. 
[13] C. H. Yang, J. F. Wuang, and F. R. Zhou, "The impact of changes in railway accessibility on regional tourism: taking the comparison of Beijing-Tianjin-Hebei and Yangtze River Delta as an example," Economic Geography, vol. 38, no. 02, pp. 188-196, 2018.

[14] I. Botha, M. Alexandru, and M. Coancă, "Innovative calculation model for evaluating regional sustainable development," Economic Computation \& Economic Cybernetics Studies \& Research, vol. 54, no. 3, pp. 5-24, 2020.

[15] J. Kim, "Blockchain technology and its applications: case studies," Journal of System and Management Sciences, vol. 10, no. 1, pp. 83-93, 2020.

[16] D. Bjelic, H. StevanovicCarapina, D. N. Markic, Z. S. Pesic, A. Mihajlov, and L. Vukic, "Environmental assessment of waste management in Banjaluka region with focus on landfilling," Environmental Engineering and Management Journal, vol. 14, no. 6, pp. 1455-1463, 2015.

[17] E. Comăniţă, P. Cozma, I. Simion, M. Roşca, and M. Gavrilescu, "Evaluation of eco-efficiency by multicriteria decision analysis. case study of eco-innovated and ecodesigned products from recyclable waste," Environmental Engineering and Management Journal, vol. 17, pp. 1791-1804, 2018.

[18] E.-D. Comanita, R. M. Hlihor, C. Ghinea, and M. Gavrilescu, "Occurrence of plastic waste in the environment: ecological and health risks," Environmental Engineering and Management Journal, vol. 15, no. 3, pp. 675-685, 2016.

[19] S. Dakak and F. Wahbeh, "Designing fast transportation network in damascus: an approach using flow capturing location allocation model," Journal of Logistics, Informatics and Service Science, vol. 7, no. 1, pp. 58-66, 2020.

[20] C. Q. Zhu, "Niche situation theory and expansion hypothesis," Acta Ecologica Sinica, vol. 17, pp. 324-332, 1997. 